\title{
Pharmacokinetics of R- and S-ketoprofen after multiple intravenous administration of ketoprofen racemate in camels
}

\author{
N. A. AlKatheeri* ${ }^{1}$, I. A. Wasfi ${ }^{1}$ and M. Lambert ${ }^{2}$ \\ ${ }^{1}$ Camel racing Laboratory, Forensic Science Laboratory, PO Box 253, Abu Dhabi, UAE \\ ${ }^{2}$ Equine Forensic Unit, Dept. of Pharmacology and Therapeutics, Trinity College, Dublin 2, \\ Ireland, ** Veterinary Research Center, Sweihan Road, PO Box 72437, Abu Dhabi, UAE
}

\begin{abstract}
The pharmacokinetics of R- and S-ketoprofen after the first and fifth intravenous (IV) dose of a daily dosage regimen of ketoprofen racemate ( $2 \mathrm{mg} \mathrm{kg}$ body weight-1) were studied in 4 female camels (Camelus dromedarius). Plasma concentrations of R- and S-ketoprofen were measured in duplicate by high performance liquid chromatography (HPLC) using a S,S-Whelk-01 chiral stationary phase column. The data obtained (mean and \pm SEM) after the first dose for $\mathrm{R}$ and S-ketoprofen, respectively, were as follows: the elimination half-lives $\left(\mathrm{t}^{1} / 2\right)$ were $1.88( \pm 0.17)$ and $1.95( \pm 0.20) \mathrm{h}$; the steady state volumes of distribution (Vss) were $93.1( \pm 2.20)$ and $100.2( \pm 2.6) \mathrm{ml} / \mathrm{kg}$; total body clearances (CLT) were $0.78( \pm 0.03)$ and $0.85( \pm 0.03) \mathrm{ml} / \mathrm{kg} / \mathrm{min}$; the areas under the curve (AUC) were $21.6( \pm 0.84)$ and $19.7( \pm 0.61) \mu \mathrm{g} / \mathrm{ml} / \mathrm{h}$. After the fifth the respective values for R and S-ketoprofen, were as follows: $t^{1} / 2$ were $1.57( \pm 0.08)$ and $1.58( \pm 0.11) \mathrm{h}$; Vss were $89.4( \pm 3.30)$ and $95.9( \pm 2.40)$ $\mathrm{ml} / \mathrm{kg}$; CLT were $0.85( \pm 0.05)$ and $0.92( \pm 0.03) \mathrm{ml} / \mathrm{kg} / \mathrm{min}$; AUC were $19.9( \pm 1.11)$ and $18.2( \pm 0.71)$ $\mu \mathrm{g} / \mathrm{ml} / \mathrm{h}$. There was no significant different in any parameters between and fifth dose.
\end{abstract}

Key Words: Pharmacokinetics, R- and S-ketoprofen, multiple dose, camels.

* Corresponding Author

\section{Introduction}

Ketoprofen [ketoprofen, ( \pm )-2-(3benzoylphenyl)-propionic acid] is nonsteroidal anti-inflammatory drug (NSAID), which is marketed as the racemate. Ketoprofen is widely used in veterinary and human medicine to treat a number of musculoskeletal conditions. Because ketoprofen contains a single chiral center it exists in two isomeric forms, the R- and Senantiomers. The ability of the NSAIDs to inhibit cyclooxygenase and therefore prostaglandin biosynthesis is thought to reside exclusively with the S-enantiomer (Hutt \& Caldwell, 1984). However, most of the side effects of these drugs are also due to cyclooxygenase inhibition (Gardner \& Simkin, 1991).

The pharmacokinetics of total ketoprofen have been reported in various species : horses (Sams et al.,1995), cattle (DeGraves et al.,1996), camels (Oukessou et al.,1995; AlKatheeri et al., 1999), donkeys (Oukessou et al., 1996), rats (Satterwhite \& Boudinot,
1992), humans (Netter et al., 1987). Recent studies in animals, however, measuring ketoprofen enantiomers after administration of racemic ketoprofen or of individual enantiomers have revealed marked stereoselective differences in ketoprofen pharmacokinetics. For example the plasma concentration - time AUC values were found to be higher for the S-ketoprofen than for the R-ketoprofen in horses (Landoni \& Lees, 1996), cats (Delatour et al., 1993), dogs (Benoit et al., 1994). In sheep, however, the reverse was reported (Delatour et al., 1993) while in humans (Rudy et al., 1998) and calves (Landoni et al., 1995) similar concentration-time profiles were observed.

We have recently studied the pharmacokinetics of ketoprofen enantiomers (AlKatheeri et al., 2000). In that study, however, we measured R- and S-ketoprofen in eight male and ten female camels after a single intravenous dose $(2.0 \mathrm{mg} / \mathrm{ml})$ of racemic ketoprofen. We found that all pharmacokinetics parameters for Rketoprofen were significantly different from 
their corresponding values of S-ketoprofen in female camels while in male camels the $\mathrm{CL}_{\mathrm{T}}$ and AUC for R-ketoprofen were significantly different from their corresponding Sketoprofen values. All pharmacokinetic parameters for R- and S-ketoprofen in female camels were significantly different from their corresponding values in male camels.

Ketoprofen, however, is usually administered in multiple doses for 3-5 days. It has been shown that for several drugs, repeated administration may result in an enhancement or a decrease of its own clearance. The objective of the present study was to evaluate the pharmacokinetics of Rand S-ketoprofen after the first and the fifth dose of a daily dosage regimen of ketoprofen so as to verify whether pharmacokinetics parameters of R- and S-ketoprofen would change with repeated IV administration of ketoprofen racemate.

\section{Materials and Methods}

Experimental animals

Four clinically healthy female camels 7 to 9 years old, and ranging in body weight from 400 to $450 \mathrm{~kg}$ were used in this study. They were kept in open pens. None had received any drug for at least 6 months. The camels were out of training for a minimum period of one year. Good quality hay and Lucerne (alfalfa) was fed once daily and water was allowed ad libitum.

\section{Experimental dosing}

Ketoprofen (ketoprofen, $100 \mathrm{mg} / \mathrm{ml}$, Nature Vet pty, limited, Richmond, Australia) was administered by a daily IV injection at 8.00 a.m. for 5 consecutive days at of dose 2 $\mathrm{mg} \mathrm{kg}$ body weight ${ }^{-1}$. Blood samples $(10 \mathrm{ml})$ were collected in heparinzed vacutainers tubes from the opposite jugular vein at 0.0 (pre-dose), 15.0, 30.0, 45.0 and 60.0 minutes, and at 1.5, 2.0, 2.5, 3.0, 4.0, 5.0, 6.0, 7.0 and
8.0 hours after drug administration. Plasma was separated by centrifugation $(2000 \mathrm{x} \mathrm{g}$ for $10 \mathrm{~min}$ ) and was stored at $-20^{\circ} \mathrm{C}$ pending analysis.

Assay procedure

The concentrations of (R-) and (S+) ketoprofen were determined by a validated HPLC method as reported previously (AlKatheeri et al., 2000).

Pharmacokinetic analysis

Pharmacokinetic characteristics of both ketoprofen enantiomers were determined by non-compartmental analysis (Gibaldi \& Perrier, 1982). The zero moment area (area under the curve, AUC) and the area under the first moment (AUMC) were determined according to the trapezoidal rule up to the last measured concentration and were extrapolated to infinity. Total body clearance (CL ) was calculated by D/AUC, where D was the dose of ketoprofen enantiomer (1 $\mathrm{mg} / \mathrm{kg}$ ). The volume of distribution at steady state $\left(\mathrm{V}_{\mathrm{ss})}\right.$ was estimated by (D x AUMC)/ $(\mathrm{AUC})^{2}$. The half-life $\left(\mathrm{t}_{1 / 2 \beta}\right)$ was calculated as 0.693 divided by the elimination rate constant $(\beta)$. The volume of distribution (area method) ( $\mathrm{Vd}_{\text {area }}$ ) was calculated by D / (AUC x $\beta$ ).

Statistical analysis of data

Values are expressed as mean and \pm SEM. Statistical of differences between pharmacokinetic parameters of enantiomers after the first dose and fifth dose were carried out using the paired student t-test. The significance level was $\mathrm{P}<0.05$.

\section{Results and Discussion}

The mean plasma ketoprofen concentration vs. time curves of Rketoprofen and S-ketoprofen after the first and fifth dose are shown in Figures 1 and 2 


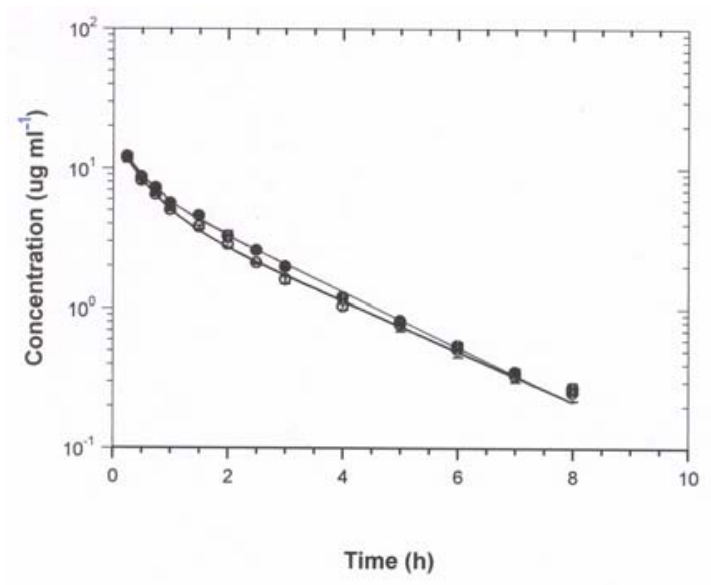

Fig. 1. R-KP (•) and S-KP (o) concentration in female camel plasma after first intravenous racemic KP administration at a dose of $2.0 \mathrm{mg}$ $\mathrm{kg}^{-1}$. Values are mean $\pm \operatorname{SEM}(\mathrm{n}=4)$

respectively. After the first and fifth dose the plasma concentration of R-ketoprofen was slightly higher than that of Sketoprofen at almost every time point. Values of the pharmacokinetic parameters are shown in table 1 . The Vss value of Rketoprofen after the fifth dose was significantly lower than that of Sketoprofen. All other values of Rketoprofen were not significant different

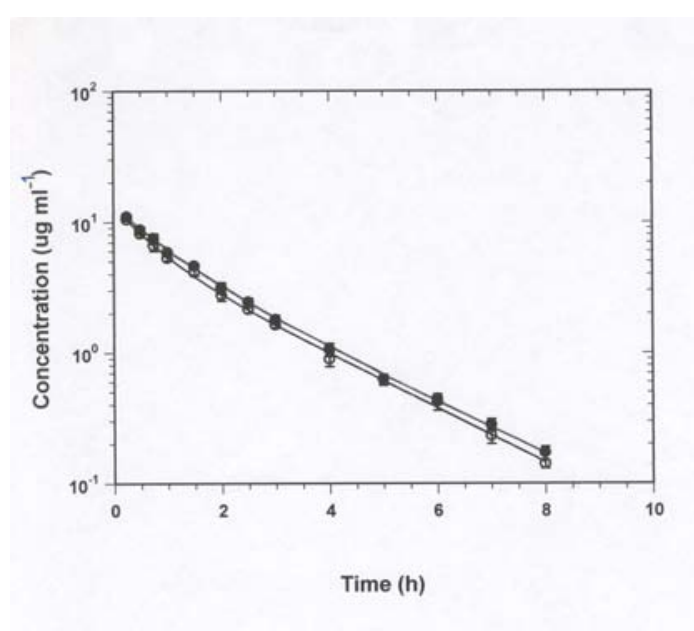

Fig. 2. R-KP (•) and S-KP (o) concentration in male camel plasma after last intravenous racemic KP administration at a dose of 2.0 $\mathrm{mg} / \mathrm{kg}$. Values are mean $\pm \operatorname{SEM}(\mathrm{n}=4)$

from S-ketoprofen values. After the first dose the values of CL, Vss, $\mathrm{Vd}_{\text {area }}$ of Sketoprofen were significantly higher than those of R-ketoprofen while the $\mathrm{AUC}_{\infty}$ of S-ketoprofen was significantly smaller than that of R-ketoprofen. The present results corroborate our previous findings (AlKatheeri et al., 2000). However, the pharmacokinetic values of R-ketoprofen

Table 1. Pharmacokinetic parameters of ketoprofen enantiomers in female camels $(n=4)$ after the first and fifth daily i.v. doses of $2 \mathrm{mg}$ of racemic ketoprofen per $\mathrm{kg}$ body weight Data expressed as mean \pm SEM.

\begin{tabular}{|c|c|c|c|c|c|c|c|}
\hline & & $\begin{array}{c}\mathbf{A U C} \\
\mu \mathrm{g} / \mathbf{m l} / \mathbf{h}\end{array}$ & $\begin{array}{c}\mathrm{CL}_{\mathrm{T}} \\
\mathrm{ml} / \mathrm{kg} / \mathrm{min}\end{array}$ & $\begin{array}{c}T_{1 / 2 \beta} \\
h\end{array}$ & $\begin{array}{c}\text { Vss } \\
\mathrm{ml} / \mathrm{kg}\end{array}$ & $\begin{array}{l}\mathbf{V d} d_{\text {area }} \\
\mathrm{ml} / \mathbf{k g}\end{array}$ & $\begin{array}{c}\text { AUMC } \\
\mu \mathrm{g} / \mathrm{ml} / \mathrm{h}\end{array}$ \\
\hline First & \multirow{2}{*}{$\mathrm{R}$} & $21.6 \mathrm{a}$ & $0.78 \mathrm{a}$ & 1.88 & $93.1 \mathrm{a}$ & $124.9 \mathrm{a}$ & 43.4 \\
\hline Dose & & \pm 0.84 & \pm 0.03 & \pm 0.17 & \pm 2.20 & \pm 7.20 & \pm 2.5 \\
\hline \multirow{6}{*}{$\begin{array}{l}\text { Fifth } \\
\text { dose }\end{array}$} & \multirow{2}{*}{$\mathrm{S}$} & 19.7 & 0.85 & 1.95 & 100.2 & 142.4 & 38.8 \\
\hline & & \pm 0.61 & \pm 0.03 & \pm 0.20 & \pm 2.60 & \pm 10.5 & \pm 2.4 \\
\hline & \multirow{2}{*}{$\mathrm{R}$} & 19.9 & 0.85 & 1.57 & $89.4 a$ & 114.7 & 35.4 \\
\hline & & \pm 1.11 & \pm 0.05 & \pm 0.08 & \pm 3.30 & \pm 7.40 & \pm 2.76 \\
\hline & \multirow{2}{*}{$\mathrm{S}$} & 18.2 & 0.92 & 1.58 & 95.9 & 125.8 & 31.7 \\
\hline & & \pm 0.71 & \pm 0.03 & \pm 0.11 & \pm 2.40 & \pm 10.5 & \pm 1.70 \\
\hline
\end{tabular}

$\mathrm{t}_{s \_\beta}=$ half - life of elimination; $\mathrm{AUC}=$ area under the curve to infinity; Vss $=$ volume of distribution at steady state; $\mathrm{Vd}_{\text {area }}=$ volume of distribution based on area under the curve to infinity; $\mathrm{CL}_{\mathrm{T}}=$ total body clearance; $\mathrm{CL}_{\mathrm{r}}=$ renal clearance; $\mathrm{MRT}=$ mean residence time; $\mathrm{AUMC}=$ area under first moment curve. $\mathrm{a}=$ significantly different for corresponding antipode in the same dose. 
and S-ketoprofen were not significantly different between the first and last dose.

The large AUC of R-ketoprofen relative to S-ketoprofen observed after the first dose might have also resulted from a slower clearance and /or a smaller volume of distribution of R-enantiomer. The small volume of distribution is probably secondary to the high protein binding $(>98 \%)$ a feature which is common to this class of drugs. It is possible that the slightly higher protein binding of R-ketoprofen observed in female camels (AlKatheeri et al., 2000) might have contributed to the higher AUC of the R-ketoprofen relative to its antipode. Profens, however, are known to undergo a metabolic transformation leading to partial inversion through a stereospecific conjugation with $\mathrm{CoA}$ and subsequent epimerization (Mayer, 1990; Caldwell et al., 1988; Nakamura \& Yamaguchi,1987). The bioinversion is usually unidirectional from the $(\mathrm{R})$ to $(\mathrm{S})$ enantiomers, although in some species the opposite has been reported (Tanaka et al., 1992). The degree of chiral inversion is drug and species-dependent. This process might have also contributed to sterioselectivity observed in camels.

In conclusion, this study did not demonstrate significant difference of pharmacokinetic parameters of ketoprofen enantiomers following repeated administration of racemate ketoprofen in female camels.

\section{Acknowledgments}

The support of Lt. Col. Ibrahim AlHowsani Director of the Forensic Science Laboratory is highly appreciated. The authors thank Dr. B. Agha, S. Mousa, O. Mohamad, N. Ali for technical Assistance. Special thanks to Photography Department, Forensic Science Laboratory and to Dr. Ismail Yousif at The Traditional Reviving
Society for housing and taking care of the camels.Ketoprofen enantiomer standards were a kind gift from Prof. P. Lees ( The Royal Veterinary College, UK).

\section{Reference}

AlKatheeri, Nawal, A., I. A. Wasfi and M. Lambert. 1999. Pharmacokinetics and metabolism of ketoprofen after intravenous and intramuscular administration in camels. J. Vet. Pharmacol. Therap. 22:127-135.

AlKatheeri, Nawal, A., I. A. Wasfi, M. Lambert, A. Saeed, and I. A. Khan. 2000. Pharmacokinetics of ketoprofen after intravenous administration of racemate in camels: effect of gender. J. Vet. Pharmacol. Therap. 23:137-143.

Benoit, E., A. Soraci and P. Delatour. 1994. Chiral inversion as a parameter for interspecies and intercompound discrepancies in enantiospecific pharmacokinetics. 6th International Congress European Association for Veterinary Pharmacology and Toxicology, Blackwell Scientific Publications. Edinburgh 7-11 August. S5/7, 07.

Caldwell, J., A. J. Hutt and S. FournelGigleux. 1988. The metabolic chiral inversion and dispositional enantioselectivity of 2-arylpropionic acids and their biological consequences. Biochem. Pharmacol. 37:105-114.

DeGraves, F. J., M. G. Riddell and J. Schumacher. 1996. Ketoprofen concentration in plasma and milk after intravenous administration in dairy cattle. A. J. Vet. Res. 57:1031 - 1033.

Delatour, P., E. Benoit, M. Bourdin, M. Gobron, and F. Moysan. 1993. Enantiosélectivité comparée de la 
disposition de deux anti-inflammatories non stéroïdiens, le kétoprofèn et le carprofêne, chez l'hoet l'animal. Bulletin dl'Académie Nationale de Mdecine 177, 515-527.

Gardner, G. C. and P. A. Simkin. 1991. Adverse effects of NSAIDs. Pharmaceu. Therap. 16:750-756.

Gibaldi, M. and D. Perrier. 1982. Non compartmental analysis based on statistical moment theory. In: Pharmacokinetics. Ed. J. Swarbrick. Dekker M. pp. 409 - 417. Plenum Press, New York.

Hutt, A J. and J. Caldwell. 1984. The importance of stereochemistry in the clinical pharmacokinetics of the 2arylpropionic acid non-steroidal antiinflammatory drugs. Clin. Pharmacok. 9:371-373.

Landoni, M. F., F. M. Cunningham and P. Lees. 1995. Pharmacokinetics and pharmacodynamics of ketoprofen in calves applying PK/PD modeling. J. Vet. Pharmacol. Therap. 18:315-324.

Landoni, M. F. and P. Lees. 1996. Pharmacokinetics and pharmacodynamics of ketoprofen enantiomers in the horse. J. Vet. Pharmacol. Therap. 19: 466-474.

Mayer, J. M. 1990. Stereoselective metabolism of anti-inflammatory 2arylpropionates. Acta Pharmacologica Nordica 2, 197-216.

Nakamura, Y. and T. Yamaguchi. 1987. Stereoselective metabolism of 2phenylpropionic acid in rat. 1) In vitro studies on the stereoselective isomerization and glucuronidation of 2- phenylpropionic acid. Drug Metab. Dispos. 15:529-534.

Netter, P., B. Bannwarth, F. Lapicque, J. M. Harrewyn, A. Frydman, J. N. Tomisier, A. Gaucher. And R. J. Royer. 1987. Total and free ketoprofen in serum and synovial fluid after intramuscular injection. Clin. Pharmacol. 42: 555 561.

Oukessou, M., F. Bouljihad, G. F. Van and M. Alvinerie. 1996. Pharmacokinetics of ketoprofen in the donkey (Equus asinus). J. Vet. Medicine. A. 43:423 426.

Oukessou, M., R. Zin-Filali, G. F. Van and M. Alvinerie. $1995 . \quad$ Ketoprofen pharmacokinetics in the camel (Camelus deromedarius). Indian Vet. J. 72: 233 236.

Rudy, A. C., Y. Liu, C. Brater and S. D. Hall. 1998. Stereoselective pharmacokinetics and inversion of (R)- ketoprofen in healthy volunteers. J. Clin. Pharmacol. 38:3S-10S.

Sams, R., D. F. Gerken. And S. M. Ashcraft. 1995. Pharmacokinetics of ketoprofen after multiple intravenous doses to mares. J. Vet. Pharmacol. Therap. 18:108-116.

Satterwhite, J. H. and F. D. Boudinot. 1992. Pharmacokinetics of ketoprofen in rats. Effect of age and dose. Biopharmace. Drug Disp. 13:197-212.

Tanaka, Y., Y. Shimomura, A. Nozaki, M. Ebata, W. Takasaki, E. Sigehara, R. Hayashi. And J. Caldwell. 1992. Formation of glycine conjugate and $(\zeta)$ - and (+)-enantiomers from (+)-(S)2-phenylpropionic acid suggesting the formation of the $\mathrm{CoA}$ thioester intermediate in dogs. Chirality 4:342-34. 